\title{
Pensando a tradução com Saussure: uma outra consideração da sincronia e da diacronia
}

\author{
Sara Luiza Hoff ${ }^{1}$
}

\section{Resumo}

A tradução é uma atividade que, por vezes, implica a consideração de questões relacionadas ao tempo, posto que o texto a ser traduzido pode se originar em um momento anterior ao do ato de traduri-lo. Este trabalbo se baseia nessa perspectiva e considera como os conceitos de sincronia e diacronia, propostos por Ferdinand de Saussure, se relacionam à prática tradutória. Enquanto a leitura estruturalista de Saussure muitas vezes defenden a dissociação completa entre essas duas noções, a tradução parece evidenciar que a diacronia e a sincronia se relacionam intima e mutuamente. Portanto, o fenômeno tradutório se torna um modo de apontar para a necessidade de, em certos casos, considerar a sincronia e a diacronia conjuntamente.

Palavras-chave: Tradução. Diacronia. Sincronia. Valor

\footnotetext{
${ }^{1}$ Bacharel em Letras pela Universidade Federal do Rio Grande do Sul (UFRGS) e mestranda do Programa de Pós-graduação em Letras da UFRGS.
} 


\title{
Introdução
}

$\mathrm{Na}$ primeira página de sua introdução à sua tradução de $A$ divina comédia, de Dante Alighieri, o tradutor Jorge Wanderley reflete sobre o momento que está vivendo da seguinte maneira:

\begin{abstract}
Imagino alguém que se disponha a escrever um prefácio a alguma nova tradução de $A$ divina comédia [...]. Imagino que tome posição à sua mesa de trabalho (a mesa dócil, o árdego computador) cercado de livros, anotações, ideias e ansiedades. Pensa em quantos já o tentaram e em quantos se esforçaram diante das muralhas, mal-encaradas como o próprio Dante, ameaçadoras como o aviso da porta infernal. Sem esperança possível, começa a escrever, movido talvez por aquelas únicas atenuantes: mudaram-se os tempos, mudaram-se as vontades. Àquele que hoje escreve lhe é agora permitido conceber as suas linhas como uma pré-estrutura, texto-andaime, o que um dia será, o não ainda, o prenúncio do que em algum tempo (nunca) virá a ser, o que mais tarde (então tarde demais) se entregará à tarefa menor da consumação; de passar de potência a ato. No interior de inesperada acalmia fica então possível continuar. Sabendo o que sempre (nunca) se soube: que depois da primeira palavra escrita todas as demais se ligam a ela e a ela se referem, que tudo já foi (e nada está) escrito (WANDERLEY, 2010, p. 27).
\end{abstract}

Embora, nominalmente, esse trecho seja uma reflexão sobre a escritura do próprio prefácio da tradução, não parece haver nada que impeça de atribuir a mesma reflexão ao processo tradutório, até por este se assemelhar ao processo de escrita em vários aspectos. O tempo, para Wanderley, em princípio é visto como uma atenuante, uma oportunidade. É porque são novos tempos que lhe é facultado o escrever de um novo prefácio e, logo, a realização de uma nova tradução. Mas um olhar mais atento permite ver que o tempo também é tanto uma fonte de aflição e de preocupação - "nunca virá a ser", será "tarde demais" - e, mais especialmente, um fator agregador: tudo o que é produzido ao longo do tempo está ligado, relacionado. Nada, portanto, está isolado, pois tudo está sempre necessariamente em relação com o que já passou.

Este trabalho visa refletir justamente sobre essa relação entre o presente e o passado; mais especificamente, busca entender e relacionar alguns conceitos propostos por Ferdinand de Saussure no Curso de linguística geral (CLG) e nos Escritos de linguística geral (ELG), procurando associá-los a um pensamento sobre a tradução. Para isso, após uma apresentação e reflexão acerca desses conceitos teóricos, apresentam-se e analisam-se excertos de dois prefácios de diferentes traduções de Dom Quixote, relacionando-os aos pressupostos teóricos apresentados previamente. Com isso, espera-se obter uma nova 
perspectiva sobre o modo como a teoria saussuriana pode contribuir para o desenvolvimento do pensamento acerca da tradução.

\section{Revisitando e renovando conceitos propostos por Saussure}

A leitura estruturalista de Saussure foi muito marcante na Linguística por muito tempo. Uma das características dessa leitura é a ênfase nas supostas dicotomias, percebidas, nesse contexto, como distinções radicais e incontornáveis. Entre elas, encontra-se o par sincronia/diacronia. A consideração do primeiro elemento, segundo essa leitura, necessariamente implica a exclusão do segundo. Felizmente, no entanto, há algum tempo há os que combatem essa perspectiva, oferecendo uma nova visão, não estruturalista, acerca da teoria saussuriana. Revisitar os conceitos de sincronia e diacronia faz parte desse movimento.

Ao mesmo tempo, a associação entre o pensamento saussuriano e os estudos de tradução não é muito frequente. Porém, sendo a tradução uma atividade eminentemente linguística, que coloca em questão pelo menos duas línguas diferentes, parece ser importante pensar quais as possíveis contribuições de Saussure para a área. Nesse cenário, os conceitos de sincronia e diacronia desempenham um papel fundamental, já que uma tradução, como vista acima, muitas vezes acabará por implicar uma relação com o tempo. Assim, penso que a reflexão sobre a tradução pode constituir um ponto de apoio para retornar a Saussure. É isso que esse artigo se propõe a fazer.

A publicação das fontes manuscritas reunidas no volume Escritos de linguística geral representa um marco para a mudança de paradigma nos estudos saussurianos, possibilitando a maior propagação de uma leitura não estruturalista do genebrino. No entanto, o Curso de linguística geral continua sendo uma fonte de consulta importante de acesso aos ensinamentos de Saussure. Por isso, as duas obras serão utilizadas como base para este trabalho.

\section{Sincronia}

Para Saussure, a Linguística é uma das ciências que lidam com valores, já que a língua constitui um sistema de valores puros (SAUSSURE, 1970). Essas ciências, segundo o 
genebrino, devem distinguir entre dois eixos: o das simultaneidades, que compreende as "[...] relações entre as coisas existentes [...]" e que exclui qualquer consideração sobre o tempo, e o das sucessões, “[...] sobre o qual não se pode considerar mais que uma coisa por vez, mas onde estão situadas todas as coisas do primeiro eixo com suas respectivas transformações" (SAUSSURE, 1970, p. 95). Dentro dessa perspectiva, Pereira de Castro (2013, p. 88) explica que o genebrino considera ser impossível abordar, ao mesmo tempo, um sistema de valores em um dado momento ou no eixo do tempo. Por isso, Saussure elabora a distinção entre sincronia e diacronia ${ }^{2}$.

A sincronia corresponde ao primeiro dos eixos expostos acima. Trata-se, segundo Saussure (1970, p. 96), de “[...] tudo quanto se relacione com o aspecto estático [...]” da Linguística. Designa, ainda segundo o autor, “[...] um estado de língua [...]”, que é a única coisa que o falante reconhece: “[...] para o indivíduo falante, a sucessão deles [dos fatos de língua] no tempo não existe: ele se acha diante de um estado" (SAUSSURE, 1970, p. 9697).

Sincronia, portanto, assinala um dado estado de língua, um momento específico dentre todos os momentos possíveis da língua. A partir das definições acima, é possível entender que se trata de um estado fixo, paralisado: um instantâneo da língua, um dado instante capturado e eternizado.

Gadet (1990), porém, vai de encontro a esse posicionamento, afirmando que

[...] "sincronia" não é para ser tomada com um simples equivalente de "estado de língua", realidade empírica que permite discussões (é um momento pontual ou um período? Um período de que tamanho? A língua está sempre mudando, não podemos observar o estado sincrônico: "Somente existem estados de língua que são eternamente a transição entre o estado do dia anterior e aquele do dia seguinte", SM, p. 39). É necessário compreender a sincronia como um conceito, que permite a definição teórica de um sistema abstrato ${ }^{3}$ (GADET, 1990, p. 55, tradução minha).

\footnotetext{
${ }^{2}$ É importante notar, aqui, que, além das adições e dos comentários dos editores, nos ELG não aparece menção às palavras sincronia e diacronia e somente se encontram algumas poucas referências aos termos "sincrônico" e "diacrônico". Isso não quer dizer, entretanto, que discussões pertinentes não se encontrem elaboradas nesses escritos, como poderá ser observado nas citações apresentadas nas próximas seções.

${ }^{3}$ No original: "Mais « synchronie » n'est pas à prendre comme simple équivalent de " état de langue ", réalité empirique qui autorise des discussions (s'agit-il d'un moment ponctuel ou d'une période? une période de quelle dimension? la langue étant toujours en train de changer, on ne saurait observer d'état synchronique : " Il n'y a que des états de langue qui sont perpétuellement la transition entre l'état de la veille et celui du lendemain », $S M$, p. 39). Il faut comprendre synchronie comme un concept, qui permet la définition théorique d'un système abstrait".
} 
Ou seja, é impossível apreender plenamente uma sincronia, pois tudo está sujeito à ação do tempo, o tempo todo. Sincronia, desse modo, constitui somente um conceito teórico, uma conceitualização metodológica para permitir a concepção do sistema da língua. Não é, portanto, um fato empírico, uma realidade praticável.

Ainda assim, é interessante notar que, para Saussure, a sincronia parece tomar precedência, já, que, como visto acima, ele considera que ela é a única realidade que pode ser observada pelos falantes. Outras passagens corroboram essa maior importância do que é sincrônico, como um trecho do CLG que confirma que a sincronia se sobressai sobre a diacronia: "Nesse ponto, está claro que o aspecto sincrônico prevalece sobre o outro, pois, para a massa falante, ele constitui a verdadeira e única realidade" (SAUSSURE, 1970, p. 105-106). Um exemplo semelhante é um excerto dos ELG que indica que o que é diacrônico não é linguístico: "Isso só poderia ser do ponto de vista diacrônico. Ex. os daêvas. Mas isso nada constitui de linguístico" (SAUSSURE, 2004, p. 86, grifo no original).

Gadet (1990, p. 56, tradução minha) também aponta para esse fato, afirmando que "os estatutos teóricos da sincronia e da diacronia são desiguais: a sincronia recebe a preeminência, porque só os atos sincrônicos são acessíveis à consciência do locutor ${ }^{4 \%}$. Isto é, por ser a única parte da língua acessível e analisável em um dado momento, a sincronia toma uma importância maior do que as sucessões no tempo. De certa forma, isso permite entender que é na sincronia que a língua sobrevém, já que o passado, como será visto na seção seguinte, é inacessível.

Além disso, é importante notar que Choi aponta para a importância da sincronia em termos mais abrangentes, considerando-a como a verdadeira causa da inovação trazida à tona por Saussure não somente no campo da Linguística, mas nas ciências humanas em geral:

Se atribuímos a Saussure a paternidade de uma revolução que afeta não somente a linguística mas, mais em geral, as ciências humanas, é na medida em que ele teve a coragem de questionar o paradigma da história, dominante no século XIX, reconhecendo uma nova dimensão para a língua, sincrônica. A "revolução saussuriana" só poderia ser realizada

\footnotetext{
${ }^{4}$ No original: "Les status théoriques de la synchronie et de la diachronie sont inégaux: la synchronie reçoit la prééminence, parce que seuls les faits synchroniques sont accessibles à la conscience du locuteur".
} 
através de um golpe polêmico, consistindo em eliminar o fator tempo ${ }^{5}$ (CHOI, 2002, p. 94, tradução minha).

Com a sincronia, portanto, se está em um dado estado de língua, em um momento específico, geralmente o momento que se vivencia agora, o momento do presente, e a história é "esquecida", ou pelo menos relegada a um outro plano, que não interessa ao estudo linguístico. É justamente esse o plano que será abordado na seção seguinte.

\section{Diacronia}

Em diversas passagens, seja direta ou indiretamente, Saussure discorre sobre o efeito do tempo na língua. Um exemplo está no seguinte trecho: "O tempo, que assegura a continuidade da língua, tem um outro efeito, em aparência contraditório com o primeiro: o de alterar mais ou menos rapidamente os signos linguísticos e, em certo sentido, pode-se falar, ao mesmo tempo, da imutabilidade e mutabilidade do signo" (SAUSSURE, 1970, p. 89). Em outra passagem, mais abreviada mas não menos impactante, Saussure (1970, p. 91) afirma que “[...] o tempo altera todas as coisas, não existe razão para que a língua escape a essa lei universal”.

Se o tempo transforma tudo, até a língua, deve haver algum meio de estudar essas alterações. É justamente isso que cabe à Linguística diacrônica. Para Saussure, é “[...] diacrônico tudo que diz respeito às evoluções" da língua. O termo designa "[...] uma fase de evolução" (SAUSSURE, 1970, p. 96). Ou seja, a diacronia compreende as alterações produzidas na língua ao longo do tempo.

É importante observar que a divisão proposta entre sincronia e diacronia não deve levar à percepção de que a língua não é histórica. Em diversas passagens, Saussure indica o contrário. Por exemplo, ele diz que "[...] quanto mais se estuda a língua, mais se chega a compreender que tudo na língua é história, ou seja, que ela é um objeto de análise histórica e não de análise abstrata [...]” (SAUSSURE, 2004, p. 131, grifos no original). Essa passagem é seguida de outra semelhante, em que o autor afirma que "[...] toda língua apresenta, um pouco como as grandes morainas que se vê nas nossas geleiras, o painel de um prodigioso

\footnotetext{
${ }^{5}$ No original: "Si l'on attribue à Saussure la paternité d'une révolution touchant non seulement la linguistique mais plus généralement les sciences humaines, c'est dans la mesure où il a eu le courage de remettre en cause le paradigme de l'histoire, dominant au XIXe siècle, en reconnaissant à la langue une nouvelle dimension, synchronique. La «révolution saussurienne » ne pouvait s'accomplir qu'à travers un coup de force polémique consistant à mettre hors jeu le facteur temps".
} 
acúmulo de coisas trazidas através dos séculos, mas de coisas que têm uma data, e datas muito diferentes [...]" (SAUSSURE, 2004, p. 131, grifos no original).

Ou seja, ao estabelecer a distinção entre sincronia e diacronia, Saussure não parece ter tido a intenção de excluir a consideração histórica da língua, mas sim de separar uma dimensão em que a história não desempenha um papel fundamental e outra em que ela é essencial, para fins metodológicos. Com essa diferenciação, Saussure não quis dizer que não havia relação entre o tempo e um dado estado de língua, como alguns podem entender, mas sim propor duas maneiras de estudar a língua, dois pontos de vista sobre esse objeto.

Excluir a história de qualquer consideração linguística, a propósito, seria praticamente impossível, já que a língua está sempre sujeita a transformações, ao mesmo tempo em que mantém a sua unidade. Em outras palavras, ela está sempre submetida à imutabilidade e à mutabilidade, como já apontado acima. Também em suas conferências na Universidade de Genebra, Saussure explora esses tópicos, explicando que a unidade da língua no tempo e a transformação constante são princípios da língua. Diz ele que, ao lado do primeiro princípio, o da unidade da língua, está o segundo, que compreende “[...] o ponto de vista do movimento da língua no tempo, mas de um movimento que, em momento algum, já que tudo está ali, chega a entrar em conflito com o primeiro princípio, da unidade da língua no tempo. Há transformação, ainda e sempre transformação [...]” (SAUSSURE, 2004, p. 137, grifos no original).

Assim, a interpretação da proposição da separação entre sincronia e diacronia como uma maneira de excluir a história vai contra a possibilidade de reconhecer as transformações, o movimento da língua no tempo, ou seja, a parte histórica da língua, logo, contra o que o próprio Saussure declara ser um dos princípios da língua, um mecanismo fundamental.

Ainda dentro dessa perspectiva, Pereira de Castro (2013, p. 88), afirma que “o termo diacronia é criado para se distanciar de uma simples visão de história" e esclarece que não se trata, como Saussure menciona em suas conferências na Universidade de Genebra, da língua na história, mas sim da comparação de diferentes estados de língua sucessivos, isto é, da história da língua, que compreende a sucessão de fatos linguísticos ao longo do tempo. 
É justamente essa história da língua, essa sucessão de acontecimentos, que interessa à diacronia, já que ela "[...] supõe, ao contrário, um fato dinâmico, pelo qual um efeito é produzido, uma coisa executada" (SAUSSURE, 1970, p. 109). Esses fatos dinâmicos, de alguma forma, exercem influência sobre o sistema linguístico, apesar de eles não estarem relacionados: "na perspectiva diacrônica, ocupamo-nos com fenômenos que não têm relação alguma com os sistemas, apesar de os condicionarem” (SAUSSURE, 1970, p. 101).

O tempo, portanto, age sobre a língua, sobre o sistema. Mas, como visto na seção anterior, é importante lembrar que os falantes não conhecem esses efeitos, pois só têm consciência do estado de língua em que se encontram. Como aponta Cruz (2013), há

[...] uma ordem na língua em que, para a consciência dos sujeitos falantes, as mudanças, apesar de reais, não são percebidas. Em outras palavras, embora a língua tenha uma história, esta escapa à consciência dos sujeitos falantes, e essa sucessão contínua de ordem diacrônica não cessa de se dissolver na dimensão do presente, isto é, na dimensão da sincronia (CRUZ, 2013, p. 40).

Justamente por essa cisão entre história e consciência, há a necessidade de dividir as abordagens da Linguística em sincronia e diacronia: para separar, no estudo linguístico, o que é pertinente a um determinado momento e o que releva da história da língua, que não é acessível aos falantes. Resta, entretanto, um questionamento: até que ponto vai a separação entre esses dois domínios e a que ela se refere? A próxima seção tentará respondê-lo.

\section{Sincronia vs. diacronia?}

Saussure parece adotar duas perspectivas contraditórias quando se trata de sincronia e diacronia. Por um lado, ele afirma que a divisão entre essas duas formas de estudar a Linguística é absoluta, constituindo uma “[...] antinomia radical [...]” (SAUSSURE, 1970, p. 107), e que "a oposição entre os dois pontos de vista - sincrônico e diacrônico - é absoluta e não admite compromissos” (SAUSSURE, 1970, p. 98). Nos ELG, ele também afirma que “em toda parte, o estado histórico e o estado consciente são dois estados que se opõem. São os dois caminhos do signo. De onde a dificuldade, mais a necessidade, de absolutamente não misturá-los em parte alguma” (SAUSSURE, 2004, p. 104).

Por outro lado, Saussure também assinala a necessidade de considerar os dois eixos concomitantemente, ao mesmo tempo em que declara a impossibilidade de fazer isso: 
[...] quanto mais um sistema de valores seja complexo e rigorosamente organizado, tanto mais necessário se faz, devido à sua complexidade, estudá-lo sucessivamente segundo seus dois eixos [o das simultaneidades e o das sucessões]. Sistema algum apresenta esse caráter tanto quanto a língua: em parte alguma se encontra igual precisão de valores em jogo, um número tão grande e uma diversidade tamanha de termos, numa dependência recíproca tão estreita. A multiplicidade dos signos, já invocada para explicar a continuidade da língua, nos impede absolutamente de estudar-lhe, ao mesmo tempo, as relações no tempo e no sistema (SAUSSURE, 1970, p. 96).

Choi (2002, p. 95, tradução minha) debate essa questão, afirmando que "o que é problemático, no entanto, não é a possibilidade de uma distinção entre sincronia e diacronia, mas a radicalidade com que Saussure traça essa linha de demarcação ${ }^{6 "}$. O autor questiona a possibilidade de separar os dois eixos claramente e aponta para o fato de que Saussure opta por usar o termo "sincronia", que contém o segmento "cronia", correspondente a tempo, para a descrição do estado de língua. Ou seja, há tempo em um estado de língua, sendo impossível separar radicalmente a perspectiva diacrônica da perspectiva sincrônica.

Da mesma forma que existe conflito entre separação radical ou concomitância de sincronia e diacronia, há contradição também em afirmações sobre o sistema e sua relação com o tempo. Por um lado, por exemplo, o genebrino afirma que "[...] a língua constitui um sistema de valores puros que nada determina fora do estado momentâneo de seus termos" (SAUSSURE, 1970, p. 95). Ou seja, só o momento sincrônico interessa e determina o valor de uma unidade. Mas, em outros momentos, Saussure admite a relação entre as mudanças que ocorrem ao longo do tempo e o estado atual. Ele afirma que "a cada instante, a linguagem implica ao mesmo tempo um sistema estabelecido e uma evolução: a cada instante, ela é uma instituição atual e um produto do passado" (SAUSSURE, 1970, p. 16) e também que "na perspectiva diacrônica, ocupamo-nos com fenômenos que não têm relação alguma com os sistemas, apesar de os condicionarem” (SAUSSURE, 1970, p. 105). Em outra passagem, diz que "cada palavra está na intersecção do ponto de vista diacrônico e sincrônico" (SAUSSURE, 2004, p. 104). Ou seja, as ocorrências do passado, estudadas pela diacronia, influenciam o sistema no presente, objeto da sincronia.

Cruz também aponta para essa aparente contradição em Saussure, explicando que

\footnotetext{
${ }^{6}$ No original: “Ce qui fait problème pourtant, ce n'est pas la possibilité d'une distinction entre synchronie et diachronie mais la radicalité avec laquelle Saussure trace cette ligne de démarcation".
} 
Saussure, de fato, defende que os pontos de vista sincrônico e diacrônico devem ser radicalmente separados. Contudo, não se trata aí da separação entre um domínio a-histórico (a sincronia) e um domínio histórico (a diacronia). Se recolocarmos o pensamento de Saussure em seu contexto de emergência, veremos que se trata aí, antes, da separação de um domínio cujo objeto é a evolução dos sons de uma palavra considerando apenas seu invólucro material, independente de qualquer significação ou uso por um sujeito falante - é a linguagem reduzida ao seu aspecto fisiológico - e um domínio cujo objeto é a "língua viva" (Saussure, 1972: 253), isto é, a língua segundo a perspectiva dos sujeitos falantes. Com efeito, a diacronia concerne ao estudo das relações entre termos que se sucedem, substituindo-se uns aos outros no tempo, "fora de toda interação" (Saussure, 1972: 122) (CRUZ, 2013, p. 36).

Novamente, então, percebe-se que a divisão entre sincronia e diacronia é metodológica e não empírica. Não representa, portanto, que não há relação entre os domínios, que a diacronia não tem efeito sobre a sincronia, que o tempo não tenha nenhuma influência na língua. É somente uma proposta para o estudo da língua sob dois pontos de vista distintos.

Um aspecto importante a apontar na citação de Cruz acima é que, para ele, a diacronia concerne apenas o domínio fonológico. Isso se dá, ainda segundo o autor, porque fora dessa categoria “[...] penetra-se um domínio em que a língua concerne, justamente, ao sujeito falante ou, se preferirmos, penetra-se um domínio em que o 'signo' se associa a uma 'ideia', o que, para Saussure, representa 'o fenômeno primordial da linguagem' (Saussure, 2002: 47)" (CRUZ, 2013, p. 37), o que levaria a uma dificuldade para manter a separação entre sincronia e diacronia.

Nesse contexto, é importante observar que, enquanto é possível entender que, para Saussure, em muitos casos, o estudo diacrônico diz respeito principalmente à fonologia, também me parece bastante contraproducente considerar que a ação do sujeito falante sobre a língua esteja fora do tempo, ou seja, da perspectiva diacrônica. O próprio Saussure aborda a relação entre língua, tempo e massa falante, afirmando que

se se tomasse a língua no tempo, sem a massa falante - suponha-se o indivíduo isolado que vivesse durante vários séculos - não se registraria talvez nenhuma alteração; o tempo não agiria sobre ela. Inversamente, se se considerasse a massa falante sem o tempo, não se veria o efeito das forças sociais agindo sobre a língua (SAUSSURE, 1970, p. 93).

Essa passagem parece indicar a interdependência entre os três fatores nela considerados (língua, tempo e massa falante). Um sem o outro representa a estagnação, a inércia. Somente há transformação com os três fatores agindo concomitantemente. 
Ainda é preciso enfatizar que essas mudanças não deixam de ter consequências, especialmente quando se trata da noção de valor. No capítulo do CLG dedicado à fonologia, Saussure afirma, a propósito das letras, que, "quando se trata de determinar o valor duma letra, é muito importante saber qual foi, numa época anterior, o som que ela representava. Seu valor atual é o resultado de uma evolução [...]” (SAUSSURE, 1970, p. 45). Em outro excerto, ele diz que “[...] a mudança de significação não tem valor algum como fato resultante do tempo, por todos os tipos de razão, entre outras, porque essa mudança se dá a cada instante e não exclui a significação precedente, que se torna concorrente [...]” (SAUSSURE, 2004, p. 41). Ou seja, quando se dá uma mudança em uma unidade, há, de certa forma, uma conservação do passado, ao menos quando se considera o seu valor. O que a unidade era não é excluído, mas passa a coexistir de algum modo com o que ela representa na época posterior à mudança.

Nesse ponto, é possível contemplar a metáfora do xadrez para tentar obter maiores elucidações sobre o assunto. Ao fim de uma longa analogia com uma partida, em que Saussure compara a sincronia a uma posição do jogo e o fato diacrônico ao deslocamento de peças, ele afirma que

numa partida de xadrez, qualquer posição dada tem como característica singular estar libertada de seus antecedentes; é totalmente indiferente que se tenha chegado a ela por um caminho ou outro; o que acompanhou toda a partida não tem a menor vantagem sobre o curioso que vem espiar o estado do jogo num momento crítico; para descrever a posição, é perfeitamente inútil recordar o que ocorreu dez segundos antes. Tudo isso se aplica igualmente à língua e consagra a distinção radical do sincrônico e do diacrônico (SAUSSURE, 1970, p. 105).

De certa forma, essa passagem parece contradizer o parágrafo anterior, em que sustento que a mudança ocorrida deixa um rastro na unidade resultante, ou seja, que aquilo que cabe à diacronia tem um efeito sobre a sincronia. Porém, é importante ir além de uma simples contraposição desses dois pontos de vista e buscar uma justaposição das afirmações. Desse modo, embora para o falante o caminho pelo qual uma unidade passa no processo de mudança seja realmente indiferente, só importando a posição atual do jogo, ou seja, a sincronia em que ele se inscreve, isso não significa que o caminho não tenha nenhum efeito sobre o estado atual do jogo; pelo contrário, é justamente a combinação de jogadas ao longo do tempo que garante a configuração da partida em um dado momento. Ou seja, mesmo que o modo como se chegou a um determinado estado (seja do jogo ou da língua) 
não seja relevante para um observador ou para um usuário da língua, é impossível deixar de reconhecer que ele pode ter importância em alguns casos.

Apesar de Saussure (1970) ter afirmado que os linguistas, do mesmo modo que os falantes, só devem se interessar pelo estado que querem compreender, ignorando a diacronia, entendo que esse posicionamento não pode ser considerado válido para todos os profissionais que se ocupam da língua, justamente devido aos rastros que as alterações deixam no valor das unidades, como explanado acima, o que pode despertar o interesse de alguns estudiosos. Creio que aos tradutores, em especial, essa questão é de especial importância, posto que eles trabalham com diferentes estados - diferentes sincronias, portanto - de duas línguas distintas. Além disso, como, em alguns momentos, a prática tradutória se baseia em textos escritos em épocas diferentes, a questão diacrônica parece se integrar ao problema. Para aprofundar a reflexão sobre essas questões, busco apoio em dados coletados em textos escritos por tradutores, como será observado na próxima seção.

\section{A sincronia e a diacronia na tradução}

Entendo que textos escritos por tradutores são importantes para a valorização e a conscientização do público acerca da prática tradutória, visto que são espaços em que esses profissionais podem expor maiores detalhes sobre o processo e sobre as suas decisões, as dificuldades e as soluções encontradas, além de se configurarem como uma possível fonte de subsídios para afirmações teóricas sobre a tradução. Para este trabalho, me baseio em três textos que acompanham duas traduções recentes de Don Quijote de la Mancha, de Miguel de Cervantes, para o português brasileiro. O primeiro texto consiste na "Nota dos tradutores" da edição publicada pela Editora Record em 2005, de autoria de Carlos Ancêde Nougué e de José Luiz Sánchez. Os demais textos, por sua vez, são escritos pelo tradutor Ernani Ssó e intitulados "Nota sobre o texto" e "Reflexões de um escudeiro de Cervantes". Eles acompanham a edição de 2012 da obra de Cervantes publicada pela Penguin Classics Companhia das Letras. A escolha desses textos se deu por abordarem a tradução de um mesmo texto muito antigo e porque os tradutores abordam questões relacionadas ao tempo, considerando a sua influência nas escolhas tradutórias.

A primeira coisa que chama a atenção ao fazer a leitura dos textos analisados é que todos os tradutores mencionam terem feito suas escolhas lexicais com o auxílio de datas. 
Enquanto Nougué e Sánchez (2005, p. 15) declaram que "a grandíssima maioria das palavras que usamos surgiram ou entraram em nossa língua até o século XVII", Ssó (2012b, p. 18) fornece uma explicação mais detalhada sobre a questão, afirmando que usou “[...] preferencialmente palavras da época de Cervantes ou anteriores, mas há também algumas do século XVIII e uma pequena porção do século XIX. Do século XX? Nenhuma (espero), mesmo que eu tenha sofrido por abrir mão de "encrenca", datada de 1913"”.

Nesses casos, observa-se que os tradutores se preocuparam em não utilizar unidades lexicais que existissem em uma dada época (ou seja, em uma dada sincronia). Com a demarcação de uma data limite para considerar se uma palavra poderia ou não ser incluída no texto traduzido, portanto, nota-se que há uma intenção de, de certa forma, recuperar a sincronia do texto original na tradução.

O mesmo se observa em outros trechos, apresentados abaixo, que discutem as escolhas tradutórias para um texto antigo de um modo mais geral. No primeiro exemplo, Nougué e Sánchez abordam o suposto ideal de pura transparência - a possibilidade de enxergar a obra sem interferências - em traduções, afirmando que

não obstante, erguem-se muitas vezes contra este ideal uma série de obstáculos intransponíveis, dentre os quais, no caso do Quixote, o tempo e a altura mesma da obra. Sim, porque como traduzir uma obra de quatrocentos anos atrás e escrita por aquele que com ela não só fundou o romance universal, mas talvez nunca tenha sido igualado nesta mesma forma literária? Em que português verter o Quixote? Pô-lo em português moderno não seria propriamente traduzir, mas adaptar. Não era essa a nossa proposta. Pretendíamos traduzi-lo resolvendo como uma "equação de três incógnitas": como escreveria Cervantes o Quixote no português de sua época, mas sem perder o sabor hispânico de então, e ainda, de modo compreensível para o leitor de hoje? (NOUGUÉ; SÁNCHEZ, 2005, p. 13 , grifos dos autores).

Outro exemplo semelhante é fornecido por Ssó (2012b), que se questiona sobre a possibilidade de manter as características que apontam para a antiguidade do texto sem perder a fluência na leitura:

Como manter a atmosfera de antiguidade e ao mesmo tempo ser legível? Aí está uma boa dor de cabeça, que John Rutherford driblou em sua tradução para a Penguin. Mas nem tudo o que fica bem em inglês fica bem em português. Não tenho coragem de pôr Sancho chamando dom

\footnotetext{
7 Naturalmente, chama a atenção, aqui, o fato de que as duas traduções adotam critérios diacrônicos diferentes para as escolhas lexicais. Entretanto, como este trabalho não pretende emitir julgamentos sobre as escolhas tradutórias, limito-me a assinalar as datas escolhidas por cada tradutor.
} 
Quixote de 'você', em vez de 'vossa mercê'. De modo que fui bem mais conservador que Rutherford (SSÓ, 2012b, p. 18).

Novamente, é possível notar, nas passagens, uma preocupação com a manutenção de uma sincronia anterior e uma tentativa de apresentá-la, o mais fielmente possível, na atualidade, sem, entretanto, causar prejuízos ao leitor dessa atualidade, que deve ser capaz de compreender o texto final.

Tal preocupação, aliás, é enfatizada ainda na seguinte passagem, que explica a função das notas de rodapé propostas por Nougué e Sánchez: “[...] antes de tudo, as notas visam a contextualizar o leitor no ambiente cultural, social, político e religioso da época de Cervantes, do qual o Quixote é um magnífico afresco" (NOUGUÉ; SÁNCHEZ, 2005, p. 14, grifo dos autores). Ou seja, novamente o que parece estar em questão é uma tentativa de restauração de uma sincronia anterior, a da obra original, embora aqui não se trate somente de uma questão linguística, mas sim do ambiente em que o original foi escrito. Nesse caso, é possível entender que, por tentarem recriar essa atmosfera e fornecerem explicações sobre o contexto da época, as notas de tradução, de certa forma, muitas vezes podem constituir uma tentativa de explicar e detalhar o valor de uma dada unidade linguística em um dado momento, quando o próprio texto da tradução e/ou o idioma de chegada não consegue fazer isso.

Ainda dentro dessa perspectiva, é interessante observar que, além de declarar a opção por manter a atmosfera do original, há uma resistência em modernizar a obra, ou seja, em adotar uma sincronia mais atual na versão traduzida. Acima, foi possível observar que Nougué e Sánchez declaram que utilizar o português moderno consistiria, segundo o ponto de vista deles, na adaptação da obra, não sendo mais uma tradução. Uma opinião menos radical é fornecida por Ssó (2012b), que utiliza uma anedota para enfatizar o seu ponto de vista:

Uma solução seria modernizar a linguagem. Mas eu resisto a uma modernização, pelo menos uma modernização a ferro e fogo, porque fiquei traumatizado numa cena extremamente dramática do Império da paixão, de Nagisa Oshima. Para quem não se lembra, o filme conta uma história de adultério e assassinato no Japão de 1895. Lá pelas tantas o amante grita para a viúva - apavorada com o fantasma que aparece no poço -, nas legendas brasileiras: "Deixe de ser Amélia!" (SSÓ, 2012b, p. 18 , grifo do autor).

Essa passagem me permite entender que a resistência à atualização da obra, muitas vezes, tem a ver, novamente, com a questão do valor da unidade dentro do sistema. Ssó 
considera a utilização de uma expressão (“Amélia”) que não teria nenhum valor nem no contexto da obra original, porque não seria uma unidade dessa língua, e nem mesmo no contexto da língua de chegada, já que a expressão é mais moderna do que a data em que o filme se passa. Nesse caso, portanto, há a influência de fatores culturais e temporais na inadequação da escolha linguística e tradutória.

Outra questão interessante a observar nos textos analisados é o tratamento dado aos nomes das personagens. Nesse ponto, está-se diante de posições divergentes. Por um lado, Ssó (2012a, p. 9) afirma ter preferido “[...] manter 'dom Quixote de la Mancha' e 'Dulcineia del Toboso', em vez de 'da Mancha' e 'do Toboso', porque esses nomes já atravessaram as fronteiras há muito tempo, assim como 'Cavalheiro da Triste Figura', embora, no caso, a figura se refira ao rosto do cavaleiro". Por outro lado, Nougué e Sánchez (2005) asseveram que

de modo totalmente diverso, porém - e contrariamente aqui a todas as demais traduções do Quixote para o português -, tratamos os epítetos formados de topônimos: em vez, por exemplo, do tradicional "D. Quixote de la Mancha", pusemos D. Quixote da Mancha, pelo simples motivo de que em português não nos referimos à Espanha central como "La Mancha", mas sim como "a Mancha". Do mesmo modo, não "Dulcinéia del Toboso", mas "Dulcinéia do Toboso" (NOUGUÉ; SÁNCHEZ, 2005, p. 14-15, grifos dos autores).

Porém, é interessante notar que, ao mesmo tempo em que declaram a sua disposição para ir contra a tradição nos exemplos mencionados acima, em outros momentos esses mesmos tradutores declaram a impossibilidade de fazer isso, como quando afirmam que só adaptaram os nomes das personagens, quando, entre outros casos,

[...] seria impossível ir contra a tradição, como no caso do próprio cognome da personagem principal. Ora, quijote era a peça da armadura que cobria a coxa, cujo correspondente em português é "coxote", e não a mera transliteração "quixote". Como porém furtar-nos ao tão tradicional Quixote, do qual já há muito tempo derivaram tantos vocábulos em nosso idioma ("quixotada", "quixotesco", "quixotice", "quixótico", "quixotismo")? (NOUGUÉ; SÁNCHEZ, 2005, p. 14, grifos dos autores).

Há divergência, portanto, entre as posições dos tradutores das duas traduções e também entre as posições dos tradutores de uma mesma versão do Quixote. De qualquer forma, é interessante notar que o desacordo parece existir justamente devido à noção de valor e da consideração da diacronia que cada tradutor aparenta seguir. No caso de Ssó, ele considera que, por serem formas usadas tradicionalmente, "dom Quixote de la Mancha" e 
"Dulcineia del Toboso" são unidades que tem um valor dentro do sistema da língua portuguesa. Já Nougué e Sánchez partem do ponto de vista de que são unidades que, sendo empréstimos do espanhol, não pertencem ao sistema da língua de chegada, logo, não têm valor nessa língua. Essa explicação também é válida para a aceitação do uso de "quixote", de certa forma. Apesar de também ser um empréstimo do espanhol, é uma forma que tem valor atualmente no idioma de chegada, o português, tanto que já foi utilizada em outras criações lexicais. Assim, nesses casos, a questão do valor parece passar pela utilização da forma ao longo do tempo.

Por fim, é interessante notar que os tradutores apresentam alguns exemplos de pontos específicos das traduções que permitem avançar ainda mais nas reflexões aqui propostas. Novamente, observa-se que há diferenças entre os estilos adotados nas duas versões da obra. Nougué e Sánchez parecem preferir um texto mais enxuto, não fornecendo muitos exemplos e explicações muito longas, em geral:

De maneira geral, mantivemos o estilo de Cervantes, suas inversões sintáticas e sintagmáticas etc., bem como tudo o que morfológica e sintaticamente fosse comum ao espanhol e ao português de então: o uso da preposição de, em lugar de por, para introduzir o agente da passiva e certos complementos nominais (por exemplo "foi ferido dos soldados inimigos"); a voz passiva sintética com agente explícito (como, por exemplo, "os tiros que se deram pelos soldados"); sintagmas como "ele tinha escritas duas cartas" em vez da locução verbal "ele tinha escrito duas cartas" etc. (NOUGUÉ; SÁNCHEZ, 2005, p. 15, grifos dos autores).

Nesse caso, é possível perceber, mais uma vez, a tentativa de restauração de uma sincronia anterior, através do uso de formas gramaticais que eram comuns na época correspondente e não são mais usadas no período atual. É interessante notar que parece ser justamente porque as formas não são mais utilizadas atualmente - logo, não têm mais valor no sistema da língua - que há a necessidade de justificar e explicar o seu uso no prefácio. Desse modo, o leitor fica mais bem preparado para a experiência que vai ter ao realizar a leitura da tradução. Isso se faz necessário precisamente porque, a partir dessas escolhas pelo uso de unidades sem valor na sincronia atual, o leitor atual pode não reconhecer o texto como natural.

Ainda dentro da perspectiva da utilização de exemplos, Ssó, por sua vez, adota um estilo mais informal e prolixo, apresentando uma maior diversidade de casos específicos, como é possível observar nos seguintes trechos: 
As palavras não têm a consistência dos números. O número sete vale sete numa conta tanto em Trombudo do Norte como em Cuernavaca ou na Cochinchina. Mas sete não vale sete num texto. A palavra "sete", para nós, evoca sorte, mentira, esoterismo. Vá saber o que evoca na Cochinchina. A cultura e o lugar, alteram, ou colorem, o significado de uma palavra. O tempo, então, nem se fala. No caso do Quixote o tempo talvez seja o fator mais hostil (SSÓ, 2012b, p. 12).

E los reales sahumados? É provável que o leitor do século XIX matasse num segundo a charada da fumigação da grana, como os leitores do tempo de Cervantes.

Mas hoje? Talvez um leitor, em quinhentos ou em mil, em vez de pensar num arenque, como eu, se desse conta de que também se defuma para afugentar os maus espíritos, purificar e dar boa sorte, que é justamente o que o camponês propõe. Como passar esse sentido de modo que até gente lerda como eu entenda de estalo? (SSÓ, 2012b, p. 16, grifo do autor).

Mas e as burlas que fazem ao cavaleiro? Comigo fazem brincadeiras ou pregam peças. Burla, hoje, quer dizer muito mais logro, trapaça, que gozação, mesmo que as gozações no caso sejam logros e trapaças (SSÓ, 2012b, p. 19).

E o "discreto"? A todo momento aparece alguém discreto, no sentido de ser sensato e arguto, atilado, inteligente. [...]

Poderia ainda ter traduzido "discreto" por "esperto" em muitas situações. "Esperto" é uma palavra antiguinha: é do século XIII. Mas o peso que ela tem em português me impediu. Cervantes fala de gente de inteligência viva, não de estelionatários, digamos (SSÓ, 2012b, p. 19-20).

Em todos esses exemplos, pode-se perceber que os tradutores se preocupam com o valor das unidades tanto na época em que o original foi escrito quanto o que teriam no momento em que eles estão realizando a sua tradução. Entendem que, ao longo do tempo, as significações - e, consequentemente, os valores - mudam e que faz parte da atividade tradutória atentar para esses fatos, buscando um equilíbrio: é necessário reconstruir os valores das unidades no original e, ao mesmo tempo, não tornar a obra inacessível ao leitor contemporâneo.

Para finalizar, é importante notar que todos os exemplos apresentados nessa seção deixam claro que, quando se trata da tradução das obras ditas clássicas, se lida com diferentes sincronias: uma do texto de partida e outra do texto de chegada. Entre elas, se dá a passagem do tempo. Por isso, a diacronia adquire força quando se fala de tradução, especialmente da tradução de textos antigos. Os excertos apresentados deixam claro que os tradutores, por estarem cientes e precisarem lidar com o efeito do tempo na língua, precisam levar em conta a diacronia no seu trabalho, para serem capazes de remontar ao texto original, determinar o valor que as formas tinham, analisar as alterações que sofreram 
na perspectiva diacrônica e alcançar a melhor escolha possível para o texto de chegada. Ou seja, mesmo que Saussure tenha defendido que os estudos diacrônicos e sincrônicos tenham que ser separados, no contexto da prática tradutória, muitas vezes, as considerações sobre a diacronia podem acrescentar muito à tarefa com que os tradutores se deparam.

\section{Considerações finais}

Em um trecho dos ELG, Saussure discorre sobre o tempo da seguinte maneira:

O fato de que o Tempo intervém para alterar a língua, como intervém para modificar qualquer coisa, não parece, de início, um fato muito grave para as condições em que se coloca a ciência linguística. E eu devo acrescentar que vejo apenas uma ínfima proporção de linguistas, ou talvez nem isso, dispostos a acreditar que a questão do Tempo criou, para a Linguística, condições particulares, dificuldades particulares, questões particulares e até mesmo uma questão central, podendo acabar por cindir a Linguística em duas ciências (SAUSSURE, 2004, p. 285, grifos no original).

Ou seja, mesmo quando se trata de uma sincronia específica, a partir dessa perspectiva fica difícil considerar possível a exclusão da consideração do fator tempo, a não ser que se deseje admitir a cisão da Linguística, uma área já tão fragmentária.

Como Saussure demonstrou, enquanto, em alguns casos, por questões metodológicas, pareça ser possível - e até mesmo recomendável - excluir exposições e reflexões sobre o efeito do tempo na língua do fazer linguístico, é importante perceber que, em outros momentos, é impossível fugir de tais considerações. É o que acontece, como espero ter demonstrado aqui, da tradução - em especial a de textos antigos e/ou clássicos que, muitas vezes, envolve duas sincronias diferentes (além de, naturalmente, sempre envolver dois ou mais sistemas linguísticos diferentes). Por isso, considerar o efeito do tempo - ou, em outros termos, considerar a diacronia - na língua pode ser imprescindível para os profissionais da tradução.

Saussure, como visto anteriormente, afirma que os sujeitos falantes somente conhecem um estado de língua, ou seja, eles não têm consciência das mudanças que ocorrem ao longo do tempo. O tradutor, porém, não é um falante "normal". Ele é um profissional da língua, que desempenha suas atividades em um contexto muito específico, lidando com línguas e, às vezes, com sincronias diferentes. Por isso, não pode ignorar a 
diacronia. Deve, pelo contrário, se tornar ciente das mudanças que a língua sofre ao longo do tempo para ser capaz de executar o seu trabalho da melhor maneira possível, respeitando o texto de origem e o reproduzindo, tanto quanto possível, no texto de chegada.

Desse modo, a partir da tradução é possível perceber que a suposta cisão entre diacronia e sincronia não deve ser tomada, como foi feito durante muitos anos, como uma realidade da língua, mas sim somente como uma distinção metodológica. Na língua, tem-se o entrelaçamento dessas noções: a diacronia consiste na sucessão de sincronias, ao mesmo tempo em que tem efeitos na sincronia do presente. Eis aí um fato inevitável, como evidenciado pela prática da tradução de textos clássicos, que mostra ser impossível desconsiderar os efeitos do tempo na língua e, concomitantemente, demonstra a possibilidade de olhar para a língua sob pontos de vista distintos, sincronicamente e diacronicamente.

\section{Referências}

CHOI, Yong-Ho. Le problème du temps chez Ferdinand de Saussure. Paris: L'Harmattan, 2002.

CRUZ, Marcio Alexandre. Uma contradição aparente em Saussure: o problema da relação língua-história. In: FIORIN, José Luiz; FLORES, Valdir do Nascimento; BARBISAN, Leci Borges. Saussure: a invenção da linguística. São Paulo: Contexto, 2013, p. 33-43.

GADET, Françoise. Saussure: une science de la langue. Paris: Presses Universitaires de France, 1990.

NOUGUÉ, Carlos Ancêde; SÁNCHEZ, José Luiz. Nota dos tradutores. In: CERVANTES SAAVEDRA, Miguel de. O engenhoso fidalgo D. Quixote da Mancha. Trad. Carlos Ancêde Nougué e José Luiz Sánchez. Rio de Janeiro: Record, 2005, p. 13-16.

PEREIRA DE CASTRO, Maria Fausta. Pequeno ensaio sobre o Tempo na teorização saussuriana. In: FIORIN, José Luiz; FLORES, Valdir do Nascimento; BARBISAN, Leci Borges. Saussure: a invenção da linguística. São Paulo: Contexto, 2013, p. 87-98.

SAUSSURE, Ferdinand de. Curso de linguística geral. 2 ed. Trad. Antônio Chelini, José Paulo Paes e Izidoro Blikstein. São Paulo: Cultrix, 1970.

Escritos de linguística geral. Trad. Carlos Augusto Leuba Salum e Ana Lucia Franco. São Paulo: Cultrix, 2004. 
SSÓ, Ernani. Notas sobre o texto. In: CERVANTES SAAVEDRA, Miguel de. Dom Quixote de la Mancha. Trad. Ernani Ssó. São Paulo: Penguin Classics Companhia das Letras, 2012a, p. 9-10.

Reflexões de um escudeiro de Cervantes. In: CERVANTES SAAVEDRA, Miguel de. Dom Quixote de la Mancha. Trad. Ennani Ssó. São Paulo: Penguin Classics Companhia das Letras, 2012b, p. 11-23.

WANDERLEY, Jorge. Traduzir A divina comédia. In: ALIGHIERI, Dante. A divina comédia - Inferno. Trad. Jorge Wanderley. São Paulo: Abril, 2010, p. 27-43.

\section{Abstract}

Translation is an activity that sometimes implies matters relating to time, since the text to be translated may originate in a moment previous to the act of translation. This perspective is the basis for this study, which considers how the concepts of synchrony and diachrony, proposed by Ferdinand de Saussure, relate to the practice of translation. While the structuralist interpretation of Saussure often advocated a complete dissociation between these two notions, translation seems to indicate that diachrony and synchrony are closely and mutually related. Therefore, the translation phenomenon becomes a way of indicating that there is a need to take synchrony and diacbrony into account jointly in some cases.

Keywords: Translation. Diachrony. Synchrony. Linguistic value

Recebido em: 13/03/2018.

Aceito em: 05/07/2018. 